\title{
METODOLOGI PERHITUNGAN KOEFISIEN PERPINDAHAN PANAS KONVEKSI PAKSA FLUIDA ORGANIK PROPANA PADA KONDISI SUPERKRITIK
}

\author{
Harmen $^{1,2, *}$, Willy Adriansyah ${ }^{1}$, Abdurrachim ${ }^{1}$, Ari Darmawan Pasek ${ }^{1}$ \\ ${ }^{1}$ Program Studi Pascasarjana Fakultas Teknik Mesin dan Dirgantara, Institut Teknologi Bandung, 40194 \\ ${ }^{2}$ Jurusan Teknik Mesin, Fakultas Teknik, Universitas Lampung, 35145 \\ *Email: harmen.1969@eng.unila.ac.id
}

Diterima: 17 April 2017

Direvisi: 23 April 2017

Disetujui: 7 Mei 2017

\begin{abstract}
ABSTRAK
Penelitian tentang siklus Rankine organik superkritis mulai giat dilakukan sebagai salah satu usaha untuk meningkatkan efisiensi termal dari siklus Rankine organik. Pada kondisi superkritik, sifat-sifat termodinamika dan fisika dari fluida organik berubah dengan sangat drastis disekitar titik kritisnya. Sehingga perhitungan koefisien perpindahan panas konveksi paksa tidak dapat lagi dilakukan dengan asumsi sifat-sifat fluida konstan. Dalam penelitian ini diusulkan sebuah metodologi untuk menghitung nilai koefisien perpindahan panas pada kondisi superkritis. Propana digunakan sebagai fluida organiknya. Tipe alat pemindah panas yang dipakai adalah jenis pipa ganda aliran berlawanan arah dan perhitungan bilangan Nusselt menggunakan korelasi Dittus-Boetler dan Gnielinski. Hasil perhitungan koefisien perpindahan panas dengan menggunakan metodologi ini dapat digunakan untuk menghitung luas daerah perpindahan panas dari alat pemindah panas tipe double pipe counter flow. Selanjutnya hasil perhitungan ini perlu dibandingkan dengan nilai koefisien perpindahan panas yang diperoleh dari hasil eksperimen.
\end{abstract}

Kata kunci: superkritik, siklus Rankine organik, propana, koefisien perpindahan panas

\begin{abstract}
Supercritical organic Rankine cycle research is great interest to be done. The supercritical cycle is an effort to increase organic Rankine cycle thermal efficiency. Under the supercritical condition, the thermo-physic properties of the organic fluid is increased or decrease dramatically around its critical point. Therefore the calculation of force convection heat transfer coefficient cannot be done under constant properties assumption. In this research is proposed a methodology that can be used to calculate heat transfer coefficient in the supercritical condition of the organic fluid. Propane is used as the organic fluid. The type of heat exchanger that will be used is counter flow double pipe heat exchanger and the Nusselt number is calculated by using DittusBoetler and Gnielinski correlations. The result of Heat transfer coefficient calculation can be used to calculate heat transfer area of counter flow double pipe heat exchanger. Furthermore, the result needs to validate with heat transfer coefficient that got from experimental.
\end{abstract}

Keywords: supercritical, organic Rankine cycle, propane, heat transfer coefficient. 


\section{PENDAHULUAN}

Siklus Rankine organik/organic Rankine cycle (SRO/ORC) merupakan teknologi yang sangat dipertimbangkan untuk usaha mengkonversikan energi dari sumber-sumber panas bertemperatur rendah (seperti energi panas dari buangan industri proses, radiasi sinar matahari, pembakaran biomassa, dan panasbumi) menjadi energi listrik yang lebih berdaya guna (Baik, 2013; Javansir, 2017). Walaupun ini bukanlah suatu teknologi baru dan telah berkembang dengan baik, tapi penelitianpenelitian mengenai teknologi ini terus dilakukan terutama untuk meningkatkan efisiensi siklusnya.

Salah satu cara untuk meningkatkan efisiensi SRO adalah dengan menggunakan SRO superkritik (Schuster, 2010; Lazova, 2014). Penggunaan siklus superkritik, khususnya yang menggunakan fluida organik dan fluida kerja lainnya secara teoritik memilki efisiensi yang lebih tinggi dan biaya relatif lebih rendah. Ini disebabkan karena lebih banyak energi dari sumber panas yang dikonversikan menjadi energi mekanik dan/atau energi listrik dan merupakan sumber-sumber energi sensibel (Gu, 2001). Pada siklus superkritis beda temperatur fluida panas dan fluida dingin dalam HE lebih kecil, sehingga pemusnahan ekserginya (exergy destruction) menjadi lebih rendah (Karellas, 2008).

Penukar panas (Heat Exchanger/HE) merupakan komponen penting dari siklus ORC superkritik, dalam hal efisiensi siklus dan kelayakan ekonomi dari satu instalasi ORC. Ada banyak tantangan dalam proses desain komponen ini agar sesuai untuk kondisi operasi pada tekanan dan temperatur yang relatif tinggi. Ini di karenakan adanya perubahan sifat yang tajam dari fluida kerja organik pada tingkat keadaan superkritis. Sehingga, nilai koefisien perpindahan panas sangat tergantung pada sifat-sifat thermophysical dari fluida kerja, karenanya penting untuk mempelajari dan memahami perilaku sifat dari fluida saat terjadi perubahan dari tingkat keadaan kondisi subkritis ke superkritis (Lazova, 2015).

Sifat-sifat termo-fisik fluida organik seperti densitas dan panas spesifik berubah dengan sangat drastis disekitar daerah pseudo-criticalnya (Forooghi, 2014). Perubahan temperatur yang kecil akan menyebabkan perubahan yang signifikan dari sifat ini.
Nilai koefisien perpindahan panas konveksi dibutuhkan untuk menentukan luas permukaan perpindahan panas. Koefisien ini ditentukan secara eksperimental yang nilainya sangat tergantung pada variabel-variabel yang mempengaruhi proses konveksi seperti geometri permukaan, kondisi aliran, sifat-sifat dari fluida dan kecepatan dari fluida. Beberapa eksperimen memperlihatkan bahwa koefisien perpindahan panas sangat tergantung sekali pada sifat-sifat fluida seperti viskositas dinamik $(\mu)$, konduktifitas termal $(k)$, kerapatan $(\rho)$, dan panas spesifik $\left(c_{p}\right)$ (Cengel, 2003).

Beberapa korelasi bilangan Nusselt/koefisien perpindahan panas konveksi pada tekanan superkritis diberikan dalam (Chen, 2015). Umumnya korelasi ini dikembangkan untuk fluida kerja air. Beberapa korelasi juga dikembangkan atau berlaku untuk fluida kerja $\mathrm{CO}_{2}$. Namun belum ada korelasi yang ditemukan dan valid untuk fluida kerja organik, terutama untuk propana.

Oleh karena itu, dengan mempertimbangkan fenomena dari perubahan drastis dari sifat-sifat termo-fisika fluida organik pada tingkat keadaan superkritik yang berpengaruh sangat besar terhadap nilai koefisien perpindahan panas, maka dalam penelitian ini akan diusulkan suatu metode perhitungan nilai koefisien perpindahan panas konveksi dari fluida organik superkritis.

\section{METODE PENELITIAN}

Metodologi atau pendekatan yang akan dilakukan adalah dengan menggunakan metode perhitungan teoritis dengan terlebih dahulu melakukan analisis awal berdasarkan literaturliteratur yang digunakan. Jenis alat penukar panas yang digunakan adalah jenis pipa ganda aliran silang. Metode ini merupakan metode perhitungan koefisien perpindahan panas fluida organik superkritis. Koefisien perpindahan panas ini akan digunakan untuk menghitung luas daerah perpindahan panas dan panjang pipanya agar dapat memanaskan fluida organik dari temperatur $50^{\circ} \mathrm{C}$ sampai temperatur $120^{\circ} \mathrm{C}$ pada tekanan diatas tekanan kritisnya. Sebagai fluida pemanas digunakan oli panas dengan temperatur $150^{\circ} \mathrm{C}$. Adapun langkah-langkah perhitungannya, adalah sebagai berikut:

a. Menentukan jenis fluida organik yang digunakan berserta sifat-sifatnya. Fluida organik yang digunakan adalah 
hidrokarbon propana $\left(\mathrm{T}_{\mathrm{c}}=96,74^{\circ} \mathrm{C}, \mathrm{p}_{\mathrm{c}}=\right.$ 41,95 bar) dan sifat-sifat dari fluida untuk tekanan dan temperatur tertentu didapat dari perangkat lunak Refprop 9.1 [Lemmon,2010].

b. Menetapkan data masukkan. Sebagai input data adalah temperatur $\mathrm{T}_{\mathrm{in}, \mathrm{FO}}, \mathrm{T}_{\mathrm{in}, \mathrm{FP}}, \mathrm{p}_{\mathrm{FO}}$ dan $\mathrm{p}_{\mathrm{FP}}, \dot{\mathrm{m}}_{\mathrm{FO}}$ dan $\dot{\mathrm{m}}_{\mathrm{FP}}$, dan diameter dari pipa. Kemudian dalam perhitungan juga ditetapkan temperatur fluida organik keluar dari HE yang diinginkan.

c. Melakukan perhitungan temperatur fluida panas yang keluar dari HE. Karena pada sekitar titik pseudo-critical perubahan sifat fluida terjadi secara tajam maka perhitungan dilakukan secara bertahap dengan $\Delta \mathrm{T}$ yang kecil. Semakin rendah $\Delta \mathrm{T}$ akan semakin rendah potensi kesalahan yang terjadi. Dalam penelitian ini digunakan $\Delta \mathrm{T}=1^{\circ} \mathrm{C}$.

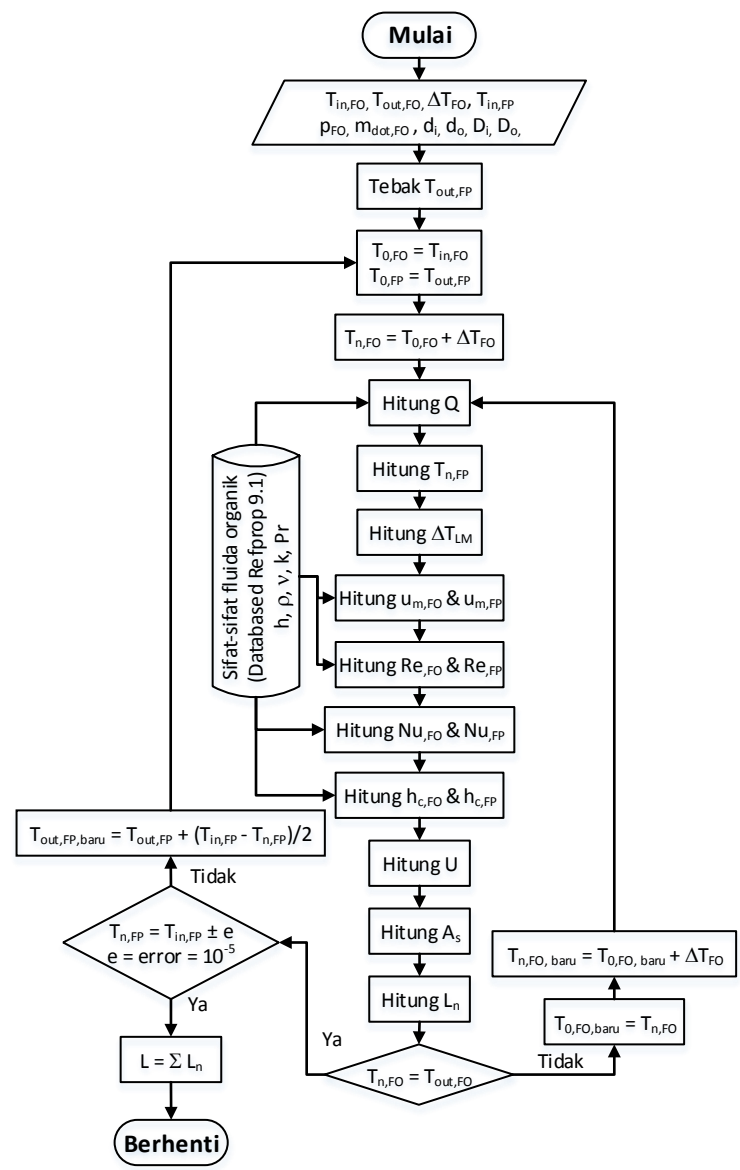

Gambar 1. Metodologi perhitungan luas daerah perpindhan panas dan panjang pipa untuk double pipe HE superkritik
Proses perhitungan selanjutnya mengikuti prosedur seperti yang diberikan pada Gambar 1.

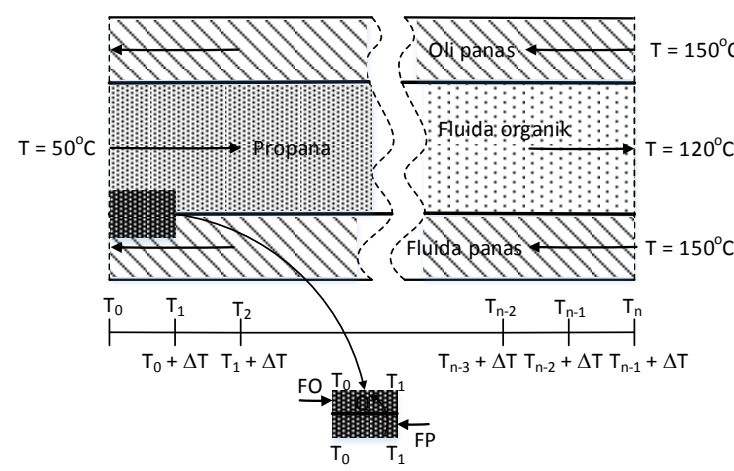

Gambar 2. Sketsa segmentasi perhitungan proses perpindahan panas

Gambar 2 memperlihatkan proses segmentasi perhitungan perpindahan panas. Pada segmen pertama $\mathrm{T}_{0} \mathrm{FO}$ sama dengan temperatur $\mathrm{FO}$ memasuki double pipe $\mathrm{HE}$ atau sebesar $50^{\circ} \mathrm{C}$. dengan $\Delta \mathrm{T}=1{ }^{\circ} \mathrm{C}$, maka $\mathrm{T}_{1, \mathrm{FO}}=51^{\circ} \mathrm{C}$. Dengan memisalkan $T_{0, F P}$ atau temperatur FP keluar dari HE, maka dengan menggunakan Persamaan $1 \mathrm{~T}_{1, \mathrm{FP}}$ dapat dihitung.

$$
T_{1, F P}=T_{0, F P}+\frac{\left\lfloor\tilde{m}\left(h_{1}-h_{0}\right)\right\rfloor_{F O}}{\left[\dot{m} c_{p}\right]_{F P}}
$$

Nilai bilangan Nusselt dari FO dihitung menggunakan korelasi Dittus-Boelter dan korelasi Gnielinski (Pers. 2 dan Pers. 3). Bilangan Nusselt dari FP dihitung melalui korelasi Dittus-Boelter.

$$
\begin{aligned}
& N u_{b}=0,023 R e_{b}^{0,8} \operatorname{Pr}_{b}^{0,4} \\
& N u=\frac{(f / 8)(R e-1000) P_{r}}{1+12,7(f / 8)^{0.5}\left(P^{2 / 8}-1\right)}
\end{aligned}
$$

Setelah nilai bilangan Nusselt untuk setiap fluida didapatkan maka nilai koefisien perpindahan panas konveksi dari masingmasing fluida dapat dihitung.

Perhitungan dilakukan sampai $\mathrm{T}_{\mathrm{n}, \mathrm{FO}}=120^{\circ} \mathrm{C}$. Kemudian dilakukan pengecekan terhadap temperatur FP masuk HE. Apabila $\mathrm{T}_{\mathrm{n}, \mathrm{FP}}=$ $150^{\circ} \mathrm{C}$ dengan error $\pm 10^{-5}$ telah tercapai, maka dilanjutkan dengan perhitungan panjang total dari HE-nya. Namun bila nilainya belum mencapai nilai tersebut diatas, maka perhitungan diulang dengan pemisalan harga temperatur FP keluar HE yang baru. 


\section{HASIL DAN PEMBAHASAN}

\section{Panas spesifik dan densitas propana pada tekanan superkritis ( $p=50$ bar)}

Salah satu karakteristik sifat-sifat termo-fisika dari fluida superkritik adalah adanya perubahan sifat yang sangat tajam pada sekitar titik pseudo-critical-nya. Pada Gambar 3 diperlihatkan dua sifat tersebut, yaitu perubahan densitas dan panas spesifik propana terhadap temperatur pada tekanan 50 bar.

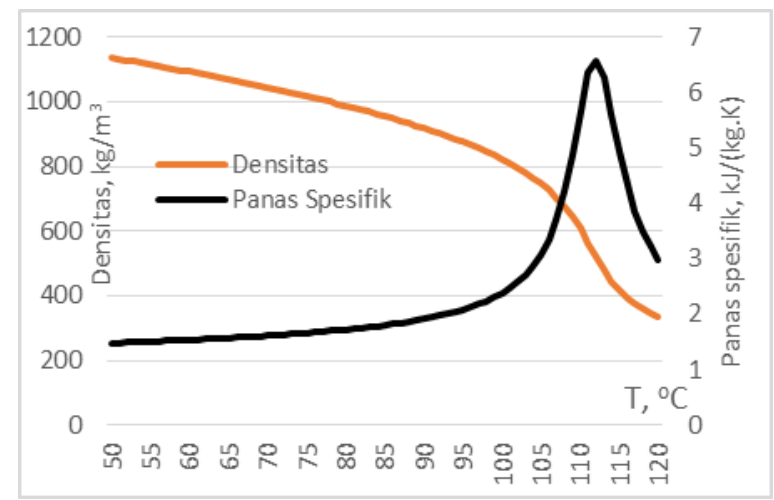

Gambar 3. Perubahan densitas dan panas spesifik propana pada kondisi superkritik ( $\mathrm{p}=$ 50 bar)

Densitas propana pada fase cair menurun dengan meningkatnya temperatur fluida. Untuk laju aliran massa dan luas penampang pipa yang konstan, maka penurunan densitas ini akan meningkatkan laju aliran fluida. Kemudian viskositas fluida juga berkurang dengan meningkatnya temperatur. Sehingga kenaikkan kecepatan dan menurunnya viskositas fluida akan meningkatkan nilai bilangan Reynolds dan seterusnya juga akan meningkatkan nilai koefisien perpindahan panas konveksinya.

Dari Gambar 3 juga terlihat bahwa adanya peningkatan nilai panas spesifik secara tajam setelah mencapai temperatur kritis sampai temperatur pseudo-critical pada tekanan 50 bar. temperatur pseudo-critical dari propana pada tekanan 50 bar ini berada antara temperatur $105^{\circ} \mathrm{C}-107^{\circ} \mathrm{C}$. Peningkatan panas spesifik akan meningkatkan kemampuan fluida untuk menyerap panas pada beda temperatur yang sama. Sehingga dari karakteristik sifatsifat termo-fisika dari fluida pada kondisi superkritik ini dapat diperkirakan akan mampu meningkatkan kemampuan fluida organik dalam menyerap energi dari sumber panas.
Selanjutnya, adanya perubahan sifat yang drastis ini membutuhkan perhitungan luas dimensi HE yang lebih detail atau perhitungan luas permukaan $\mathrm{HE}$ dilakukan untuk luas permukaan segmen yang sekecil mungkin [Schröder, 2014].

\section{Distribusi temperatur propana dan oli pada double pipe $\mathrm{HE}$}

Distribusi temperatur disepanjang pipa HE untuk setiap segmennya dihitung berdasarkan metodologi yang diberikan pada sub bagian diatas dan seperti diagram alir pada Gambar 3. Propana bertekanan 50 bar pada laju aliran volume 1 liter $/$ menit $(0,00774433 \mathrm{~kg} / \mathrm{s})$ dengan temperatur $50^{\circ} \mathrm{C}$ dipanaskan oleh oli panas dengan merek dagang Therminol ${ }^{\circledR}$ ADX-10 hingga temperaturnya mencapai $120^{\circ} \mathrm{C}$. untuk keperluan tersebut diperlukan oli panas sebanyak 10 liter/menit $(0,13648333 \mathrm{~kg} / \mathrm{s})$ bertemperatur $150^{\circ} \mathrm{C}$. distribusi temperatur propana dan oli panas digrafikkan seperti Gambar 4 berikut.

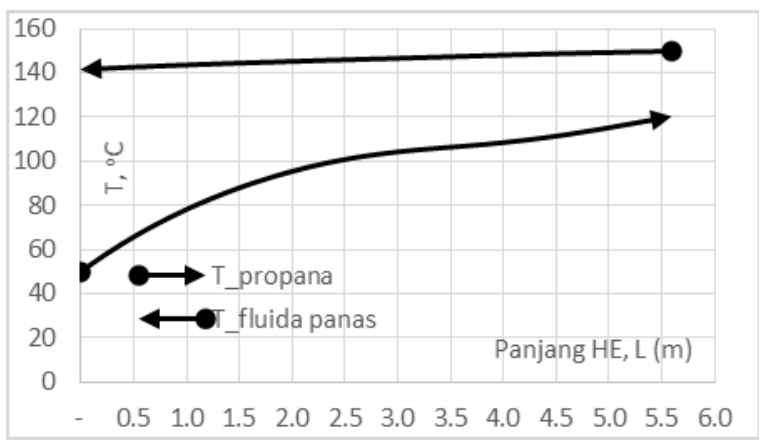

Gambar 4. Pola temperatur fluida propana pada tekanan superkritik dan distribusi temperatur oli

Pada fase cair peningkatan temperatur propana lebih cepat dibandingkan dengan peningkatan temperaturnya pada fase gas. Peningkatan temperatur ini akan semakin landai saat berada disekitar titik pseudo-critical. Ini disebabkan karena tingginya nilai panas spesifik pada kondisi tersebut. Dari pola ini juga dapat di nyatakan bahwa penggunan asumsi satu nilai $\Delta \mathrm{T}_{\mathrm{LM}}$ yang dihitung berdasarkan temperatur masuk dan temperatur keluar dari kedua fluida dalam keseluruhan perhitungan tidak dapat dilakukan (Karellas, 2012).

Temperatur oli panas keluar dari HE masih cukup tinggi yaitu sekitar $141,4394{ }^{\circ} \mathrm{C}$. perbedaan terkecil antara temperatur propana dan temperatur oli panas atau yang disebut 
juga dengan perbedaan temperatur pinch point $\left(\Delta \mathrm{T}_{\mathrm{pp}}\right)$ masih cukup besar sekitar $30^{\circ} \mathrm{C}$. Masih tingginya temperatur oli yang keluar dari $\mathrm{HE}$ menunjukkan bahwa HE masih berpeluang besar untuk dilakukan optimasi. Optimasi dapat dilakukan dengan memperkecil laju aliran massa oli dan atau meningkatkan laju aliran massa propana. Pengurangan dan peningkatan laju aliran massa fluida ini juga akan meningkatkan luas permukaan perpindahan panas dan atau meningkatkan panjang pipa.

\section{Prediksi Koefisien perpindahan panas konveksi $(h)$ dari propana pada tekanan superkritis}

Koefisien perpindahan panas konveksi propana dihitung menggunakan persamaan 4 berikut.

$$
h=\frac{N u_{k} k}{d_{i}}
$$

Nilai bilangan Nusselt dihitung menggunakan korelasi Dittus-Boelter dan korelasi Gnielinski (Pers. 2 dan Pers. 3). Hasil perhitungan koefisien perpindahan panas konveksi untuk setiap segmen sepanjang pipa HE digrafikkan seperti Gambar 5.

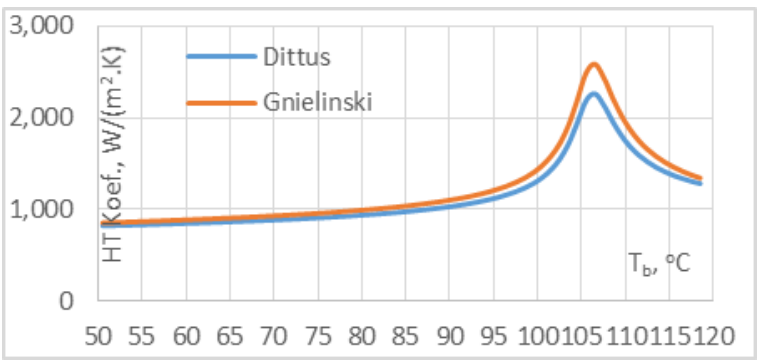

Gambar 5. Perubahan koefisien perpindahan panas konveksi terhadap temperatur pada kondisi superkritis.

Berdasarkan Gambar 5 terlihat bahwa perhitungan koefisien perpindahan panas konveksi propana dengan menggunakan kedua korelasi tersebut memperlihatkan pola yang sama. Nilai $h$ naik secara perlahan pada fase cair, kemudian setelah mencapai temperatur kritisnya naik dengan tajam sampai temperatur pseudo-critical, selanjutnya turun dengan tajam pula sampai temperatur $120^{\circ} \mathrm{C}$.

Perbedaan nilai $h$ antara korelasi DittusBoelter dan Gnielinski pada fase cair tidak besar, tapi pada sekitar titik pseudo-critical nilai ini berbeda cukup signifikan. Rata-rata perbedaannya adalah sebesar $87,97 \mathrm{~W} /\left(\mathrm{m}^{2}{ }^{\circ} \mathrm{C}\right)$ dengan perbedaan mini-mum dan maksimum sebesar 32,05 $\mathrm{W} /\left(\mathrm{m}^{2}{ }^{\circ} \mathrm{C}\right)$ dan 323,09 $\mathrm{W} /\left(\mathrm{m}^{2}{ }^{\circ} \mathrm{C}\right)$. untuk menentukan korelasi mana yang lebih valid untuk digunakkan memerlukan data eksperimental dan atau hasil simulasi sebagai pembandingnya. Besarnya nilai perbedaan ini juga akan berpengaruh terhadap perhitungan luas daerah perpindahan panas dan panjang pipanya.

Menurut (Kang, 2009), pola perubahan nilai koefisien perpindahan panas seperti ini dibagi menjadi tiga kondisi yaitu, kondisi normal, kondisi peningkatkan dan kondisi penurunan yang drastis dari nilai koefisiennya. Pola seperti ini terjadi bila temperatur dinding perpindahan panas lebih tinggi dari temperatur pseudo-critical fluida dan lebih tinggi dari temperatur curah (bulk) fluida atau $T_{w}>T_{p c}>T_{b}$.

\section{Luas permukaan perpindahan panas dan panjang pipa}

Luas permukaan perpindahan panas untuk setiap segmen dihitung dengan menggunakan Pers. 5.

$$
A_{s}=\frac{Q}{U_{s} \Delta T_{L M}}
$$

Sedangkan panjang pipanya dihitung melalui persamaan 6 berikut ini.

$$
L=U_{s}\left(\frac{1}{\pi d_{i} h_{F O}}+\frac{1}{2 \pi k}+\frac{1}{\pi d_{0} h_{F P}}\right)
$$

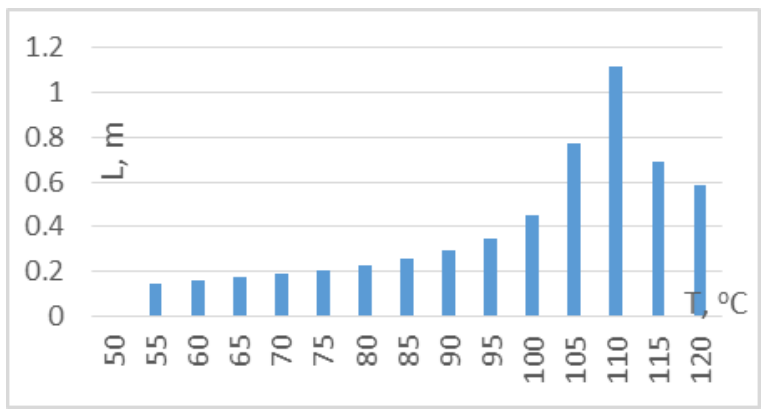

Gambar 6. Panjang pipa SHE tipe double pipe untuk memanaskan propana dari temperatur $50^{\circ} \mathrm{C}-120^{\circ} \mathrm{C}$ pada $\mathrm{p}=50$ bar.

Gambar 5 memperlihatkan pola perubahan panjang pipa SHE tipe double pipe yang digunakan untuk memanaskan propana dari temperatur $50^{\circ} \mathrm{C}-120^{\circ} \mathrm{C}$ pada tekanan 50 bar untuk setiap $5^{\circ} \mathrm{C}$ kenaikkan temperatur propana. Untuk keperluan ini total panjang pipa yang dibutuhkan adalah sebesar $5,595 \mathrm{~m}$ 
bila perhitungan bilangan Nusseltnya menggunakan korelasi Dittus-Boelter dan sebesar 5,469 m dengan menggunakan korelasi Gnielinski atau dengan perbedaan sebesar 126 $\mathrm{mm}$. Untuk laju aliran yang lebih besar, maka perbedaan ini menjadi sangat berpengaruh terhadap optimalisasi dari alat pemindah panas. Sehingga untuk mendapatkan perhitungan panjang pipa dan luas permukaan perpindahan panas yang tepat diperlukan korelasi perpindahan panas konveksi yang sesuai

\section{KESIMPULAN}

Dari hasil penelitian ini memberikan kesimpulan sebagai berikut:

1. Metodologi yang diusulkan pada penelitian ini secara teoritik dapat digunakan untuk menghitung prediksi nilai koefisien perpindahan panas dari propana pada tekanan diatas tekanan kritisnya.

2. Nilai $h$ yang dihasilkan melalui perhitungan ini dapat digunakan sebagai nilai prediksi h dalam merancang HE yang akan digunakan mendapatkan nilai $h$ dari data hasil pengujian.

3. Selanjutnya nilai $\mathrm{h}$ hasil perhitungan dari data eksperimental dan atau hasil simulasi dapat digunakan sebagai data pembanding nilai $h$ yang diperoleh dari perhitungan teoritis berbagai korelasi yang ada.

4. Untuk memanaskan propana pada tekanan diatas tekanan kritisnya (pada $\mathrm{p}=50$ bar) dari dari temperatur $50^{\circ} \mathrm{C}-120^{\circ} \mathrm{C}$ dalam $\mathrm{HE}$ tipe pipa ganda aliran silang dengan diameter pipa bagian dalam dan luarnya $d_{i}$ $=8 \mathrm{~mm}, \mathrm{~d}_{\mathrm{o}}=2 \mathrm{~mm}, \mathrm{D}_{\mathrm{i}}=22,4 \mathrm{~mm}$, dan $\mathrm{D}_{\mathrm{o}}$ $=25 \mathrm{~mm}$, diperlukan panjang pipa sebesar $5,595 \mathrm{~m}$ bila perhitungan bilangan Nusseltnya mengguna-kan korelasi DittusBoelter dan sebesar 5,469 m dengan menggunakan korelasi Gnielinski.

\section{UCAPAN TERIMA KASIH}

Penulis mengucapkan terima kasih kepada Kementrian Riset dan Pendidikan Tinggi RI yang telah memberikan dana beasiswa S3 BPPDN dan dana Hibah Penelitian Doktor TA 2017. dengan fluida yang digunakan dan kondisi operasi yang diterapkan.

Pada daerah sekitar titik pseudo-critical, dibutuhkan panjang pipa yang jauh lebih besar dari daerah lainnya untuk meningkatkan temperatur propana sebesar $5^{\circ} \mathrm{C}$. Walaupun untuk daerah ini nilai koefisien perpindahan panasnya paling tinggi, tapi pada daerah ini juga terjadi perpindahan panas yang paling tinggi.

\section{DAFTAR PUSTAKA}

Baik Y. J., Kim M., Chang K. C., Lee Y. S., dan Yoon H. K., 2013, A comparative study of power optimization in lowtemperatur geothermal heat source driven R125 transcritical cycle and HFC organic Rankine cycles, Renewable Energy vol. 54, 78-84.

Cengel, Y. A., 2003, Heat transfer: a practical approach, McGraw Hill Book Company, USA.

Chen, W., Fang, X., Xu, Y., dan Su, X., 2015, An assessment of correlations of force convection heat transfer to water at supercritical pressure, Annals of Nuclear Energy vol. 76, 452-460

Forooghi P. dan Hooman K., 2014, Experimental analysis of heat transfer of supercritical fluids in plate heat exchangers, International Journal of Heat and Mass Transfer vol. 74, 443-459.

$\mathrm{Gu}$ Z. dan Sato H., 2001, Performance of supercritical cycles for geothermal binary design, Energy Conversion and Management vol. 43, 961-971.

Javanshir A. dan Sarunac N., 2017, Thermodynamic analysis of a simple Organic Rankine Cycle, Energy vol. 118, 85-96.

Kang, K. H. dan Chang, S. H, 2009, Experimental study on the heat transfer characteristics during the pressure transients under supercritical pressures, International Journal of Heat and Mass Transfer vol. 52, 4946-4955, doi:10.1016/

j.ijheatmasstransfer.2009.06.005.

Karellas, S. dan Schuster, A., 2008, Supercritical fluid parameters in organic Rankine cycle applications, International 
Journal of Thermodynamics vol. 11, 101108.

Karellas, S., Schuster, A., dan Leontaritis, A.D., 2012, Influence of supercritical ORC parameters on plate heat exchanger design, Applied Thermal Engineering vol. 33-34, 70-76, doi:10.1016/j.applthermaleng. 2011.09.013.

Lazova M., Daelman S., Kaya A., Huisseune H., dan De Paepe M., 2014, Heat Transfer in Horizontal Tube at Supercritical Pressure for Organic Rankine Cycle applications, $\quad 10^{\text {th }} \quad$ International Conference on Heat Transfer, Fluid Mechanics and Thermodynamics 14-16 July 2014 Orlando, Florida.

Lazova M., Daenens D., Kaya A., Belleghem M.V., Kosmadakis H.H., Manolakos D., Paepe M.D., 2015, Design of a supercritical heat exchanger for an integrated $\mathrm{CPV} / \mathrm{T}$ Rankine cycle, $3^{\text {rd }}$ International Seminar on ORC Power Systems, 2-4 Oktober 2015, Brussels, Belgia.

Lemmon E.W., Huber M.I., McLinden M.O., 2010, NIST standard reference database 23: Reference Fluid Thermodynamic and Transport Properties-REFPROP, version 9.1, National Institute of Standard and Technology, Standard Reference Data Program, The U.S. secretary of Commerce.

Schuster A., Karellas S., dan Aumann R., 2010, Efficiency optimization potential in super-critical Organic Rankine Cycles, Energy vol. 35, 1033-1039.

Schröder, E., Neumaier, K., Nagel, F., dan Vetter, C., 2014, Study on heat transfer in heat exchangers for a new supercritical organic Rankine cycle, Heat Transfer Engineering, vol. 35, 1505-1519. 
